Technical Note

\title{
Integration of Hyperspectral Shortwave and Longwave Infrared Remote-Sensing Data for Mineral Mapping of Makhtesh Ramon in Israel
}

\author{
Gila Notesco *, Yaron Ogen and Eyal Ben-Dor \\ Remote Sensing Laboratory, Tel Aviv University, Tel Aviv 69978, Israel; yaronogen@gmail.com (Y.O.); \\ bendor@post.tau.ac.il (E.B.-D.) \\ * Correspondence: gilano@post.tau.ac.il; Tel.: +972-3-640-5679 \\ Academic Editors: Magaly Koch and Prasad S. Thenkabail \\ Received: 1 February 2016; Accepted: 7 April 2016; Published: 9 April 2016
}

\begin{abstract}
Hyperspectral remote-sensing in the reflected infrared and thermal infrared regions offers a unique and efficient alternative for mineral mapping, as most minerals exhibit spectral features in these regions, mainly in the shortwave and longwave infrared. Airborne hyperspectral data in both spectral regions, acquired with the AisaFENIX and AisaOWL (Specim) sensors over Makhtesh Ramon in Israel, were analyzed. Calculating the reflectance and emissivity spectra of each pixel in the shortwave infrared and longwave infrared region images, respectively, and determining mineral indices enabled identifying the dominant minerals in this area-kaolinite, calcite, dolomite, quartz, feldspars and gypsum-and mapping their spatial distribution in the surface. The benefit of using hyperspectral data from both reflected infrared and thermal infrared regions to improve mineral identification was demonstrated.
\end{abstract}

Keywords: hyperspectral remote sensing; reflected infrared region; thermal infrared region; Makhtesh Ramon; mineral mapping

\section{Introduction}

Remote-sensing techniques, using spaceborne and airborne sensors in the infrared region, offer an efficient method for mineral mapping (e.g., [1-4]), as most minerals exhibit spectral features in the reflected infrared (RIR) - mainly shortwave infrared (SWIR, 1.0-2.5 $\mu \mathrm{m}$ ), and thermal infrared (TIR) - mainly longwave infrared (LWIR, 8.0-13.0 $\mu \mathrm{m}$ ) regions. For example, clay minerals, carbonates and gypsum can be detected in both the RIR and TIR regions, whereas feldspars and quartz can be detected only in the TIR, mainly LWIR region. Merging both RIR and TIR regions' data enables to identify a variety of minerals and mapping their distribution in the surface, as shown in several studies (e.g., $[5,6])$.

In a previous study [7], we developed a procedure based on comparing day and night LWIR region hyperspectral (henceforth LWIR) data acquired with the AisaOWL (Specim) sensor over Makhtesh Ramon in Israel, for mineral mapping. Dominant minerals—quartz, feldspars, clay minerals, gypsum and carbonates-were identified and their distribution was mapped. Pursuant to those results, we extended the study by adding the SWIR region hyperspectral (henceforth SWIR) data acquired with the AisaFENIX (Specim) sensor. Herein we examine the benefit of combining the LWIR and SWIR data for mineral mapping. 


\section{Materials and Methods}

\subsection{The Study Area and Airborne Data}

Makhtesh Ramon, an eroded anticline, $40 \mathrm{~km}$ long and $7 \mathrm{~km}$ wide, with a total area of about $200 \mathrm{~km}^{2}$, is located in the Negev desert in Southern Israel, as described by Notesco et al. [7]. The surface consists of a variety of minerals and rock types, including clay minerals, calcite, dolomite, gypsum, iron oxides, chert, marl, basalt, tuff, andesite and sandstone. It is an ideal site for examining new remote-sensing technology and ideas, being an arid area with extremely sparse vegetation and cloudless most of the year [8].

The airborne data, two flight lines covering a total area of $15 \mathrm{~km}^{2}$ (Figure 1), were acquired during two flight campaigns. The LWIR data were acquired with Specim's AisaOWL sensor, covering the 7.7-12 $\mu \mathrm{m}$ spectral range, as described by Notesco et al. [7]. The SWIR data were acquired with Specim's AisaFENIX sensor, covering the $0.4-2.5 \mu \mathrm{m}$ spectral range with 448 spectral bands and a FWHM of 0.0035-0.0055 $\mu \mathrm{m}$ [9], on 19 September 2014 at 08:50 UTC. The flight altitude was $1.34 \mathrm{~km}$ above ground level, resulting in a spatial resolution of $2 \mathrm{~m}$, as in the LWIR data.

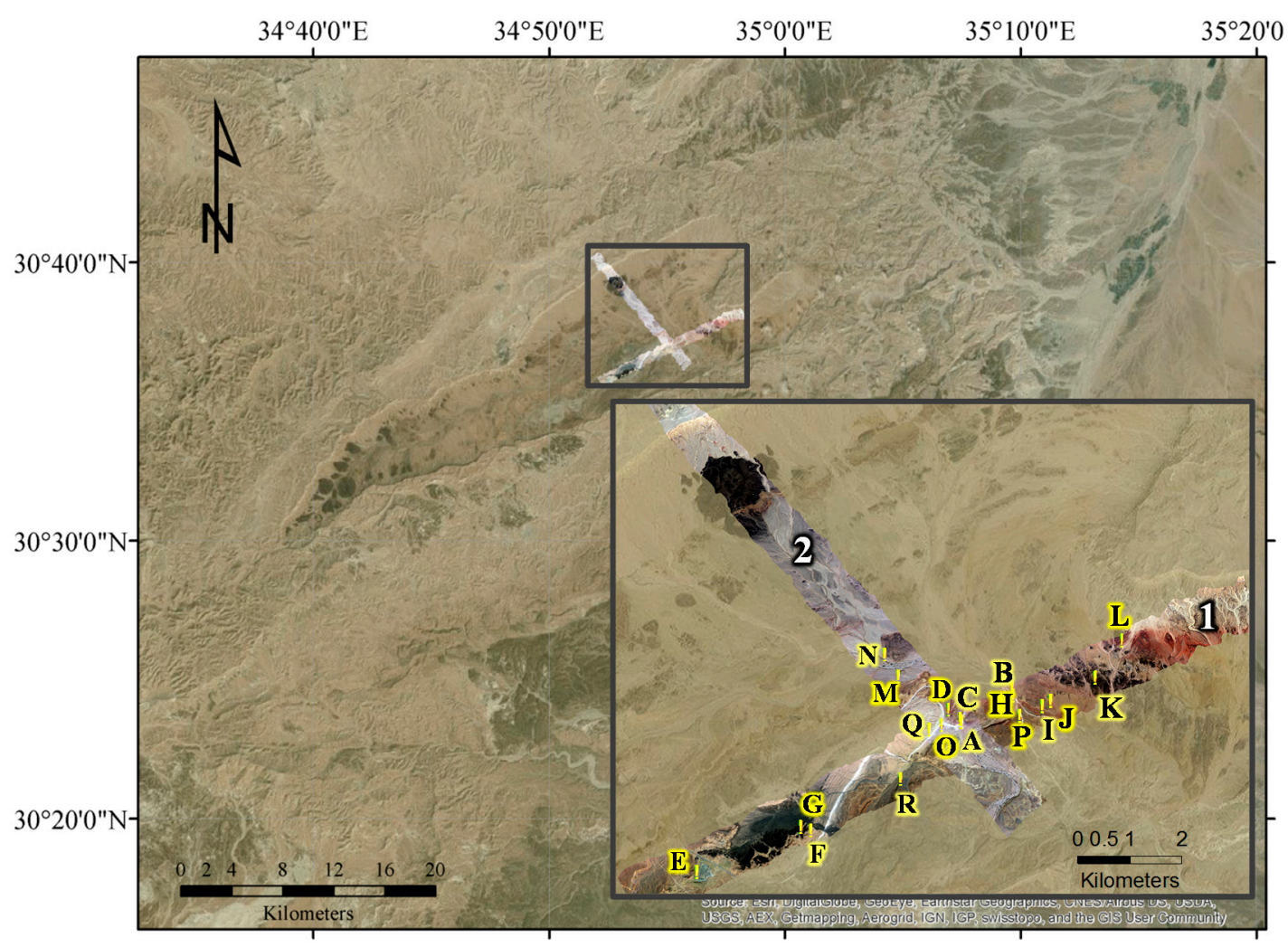

Figure 1. The study area (image source: Esri, DigitalGlobe, GeoEye, Earthstar Geographics, CNES/Airbus DS, USDA, USGS, AEX, Getmapping, Aerogrid, IGN, IGP, swisstopo, and the GIS User Community), the two flight lines ( 1 and 2 ) and the location of 18 regions of interest (ROIs). Each ROI, consisting of more than 10 pixels, represents hundreds of square meters of a uniform surface that was sampled and measured with an X-ray diffractometer (XRD) as described by Notesco et al. [7]. The XRD analysis results are shown below in Table 1 .

\subsection{Data Analysis}

Absorption features in the SWIR reflectance of clay minerals (at 1.4 and $2.2 \mu \mathrm{m}$ ), gypsum (at 1.4-1.5, 1.75, 1.9 and $2.2 \mu \mathrm{m}$ ), and carbonates (at $2.3 \mu \mathrm{m}$ ) are due to vibration modes in the hydroxyl functional groups, water molecules and carbonate ion, respectively. Spectral features in the 
LWIR emissivity of silicates (quartz, feldspars and clay minerals at 8.3-9.5 $\mu \mathrm{m}$ ), gypsum (at $8.6 \mu \mathrm{m}$ ) and carbonates (at $11.3 \mu \mathrm{m}$ ) are due to vibration modes of the silicon-oxygen bond ( $\mathrm{Si}-\mathrm{O}$ ), sulfur-oxygen bond $(\mathrm{S}-\mathrm{O})$ and carbon-oxygen bond $(\mathrm{C}-\mathrm{O})$, respectively [10-13].

\subsubsection{SWIR Data Analysis}

Each radiance image acquired with the AisaFENIX sensor was atmospherically corrected using ACORN-6 software (ImSpec LLC, Advanced Imaging and Spectroscopy), resulting in a reflectance image, followed by continuum removal normalization in specific spectral ranges to emphasize indicative absorption features [14,15], between 2.12-2.24 $\mu \mathrm{m}$ and between 2.26-2.37 $\mu \mathrm{m}$, indicative of clay minerals and carbonates, respectively, as demonstrated in Figure 2. A pixel in the normalized reflectance image between 2.12 and $2.24 \mu \mathrm{m}$ was classified as clay if $\mathrm{NR}_{2.20 \mu \mathrm{m}} \leqslant 0.90$, where NR is the normalized reflectance value at the indicated wavelength. Furthermore, kaolinite could be identified with a ratio $\left(\mathrm{NR}_{2.16 \mu \mathrm{m}}-\mathrm{NR}_{2.20 \mu \mathrm{m}}\right) /\left(\mathrm{NR}_{2.23 \mu \mathrm{m}}-\mathrm{NR}_{2.20 \mu \mathrm{m}}\right)<1$, whereas for other clay minerals this ratio is $\geqslant 1[16,17]$, as demonstrated in Figure 2a for kaolinite, illite and montmorillonite with ratios of $0.28,1.04$ and 1.22, respectively. A pixel in the normalized reflectance image between 2.26 and $2.37 \mu \mathrm{m}$ was classified as dolomite or calcite based on the absorption at 2.32 or $2.34 \mu \mathrm{m}$, respectively, as demonstrated in Figure 2b.
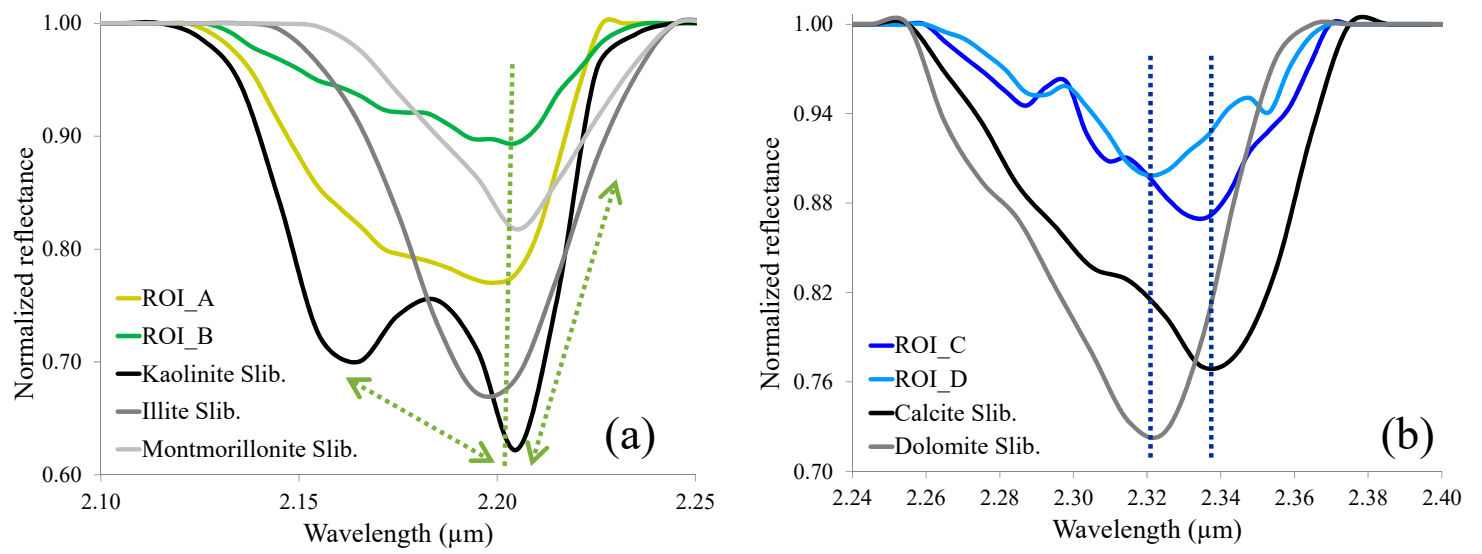

Figure 2. (a) Spectra of regions of interest (ROIs) A and B from the normalized reflectance image and of clay minerals from a spectral library (Slib.) [12] for comparison, with the indicative absorption feature at $2.20 \mu \mathrm{m}$; (b) Spectra of ROIs C and D from the normalized reflectance image and of carbonates from the spectral library, with indicative absorption features at 2.32 and $2.34 \mu \mathrm{m}$ of dolomite and calcite, respectively.

\subsubsection{LWIR Data Analysis}

The LWIR data analysis procedure was described by Notesco et al. [7] as "The Gain Spectrum Approach". Briefly, the at-sensor radiance of each pixel in the image was divided by a tangent blackbody radiation curve, resulting in an Ls (at-sensor radiance)/Lb (fitted blackbody radiation curve) image. The spectrum of each pixel in the Ls/Lb image was divided by a gain-factor spectrum, derived from the Ls/Lb spectrum of an in situ surface, reducing the atmospheric contribution and emphasizing mineral-related features, and resulting in an approximate emissivity image. Dominant minerals-quartz, feldspars, clay minerals, gypsum and carbonates-were identified by using the continuum removal-based indices given by Notesco et al. [7].

\section{Results and Discussion}

Mineralogical maps of the surface of Makhtesh Ramon, based on the analyses of the SWIR and LWIR images, are shown in Figure 3. Clay minerals and carbonates-calcite and dolomite-were 
identified based on the SWIR region data (Figure 3a). More than $95 \%$ of the pixels identified as clay minerals resulted in a ratio $\left(\mathrm{NR}_{2.16 \mu \mathrm{m}}-\mathrm{NR}_{2.20 \mu \mathrm{m}}\right) /\left(\mathrm{NR}_{2.23 \mu \mathrm{m}}-\mathrm{NR}_{2.20 \mu \mathrm{m}}\right)<0.75$, e.g., 0.35 and 0.59 in ROIs A and B (Figure 2a), respectively, and were therefore identified as kaolinite. Identifying gypsum based on the SWIR image was problematic because of its spectral features' proximity to atmospheric water vapor $(1.40,1.90 \mu \mathrm{m})$ and clay minerals $(2.20 \mu \mathrm{m})$ features. Quartz, feldspars, clay minerals, gypsum and carbonates were identified based on the LWIR region data (Figure $3 b$ ).
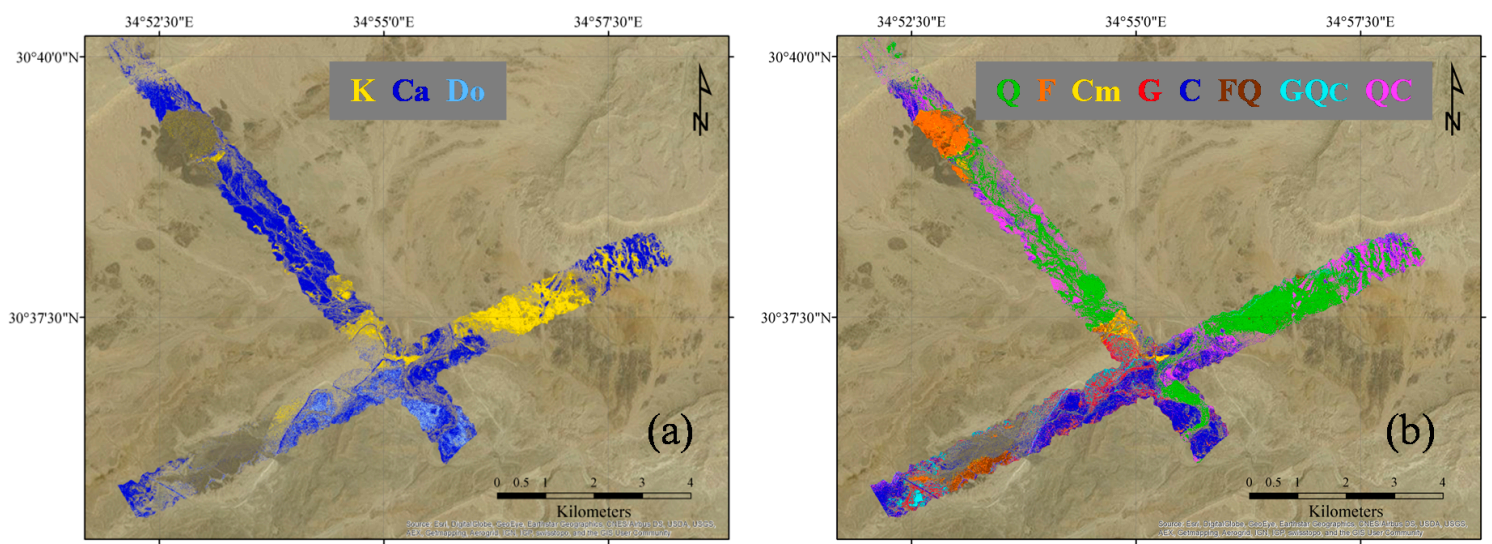

Figure 3. Mineral map of the surface covered by the two flight lines in Makhtesh Ramon based on the SWIR (a) and LWIR (b) images. K-kaolinite, Ca-calcite, Do-dolomite, Q-quartz, F-feldspars, Cm-clay minerals, G-gypsum, C-carbonates, FQ-feldspars + quartz, GQC-gypsum + quartz (+ carbonates), QC-quartz + carbonates.

Classification of the dominant minerals resembled the XRD analysis results of selected rock samples collected from the study area (Table 1).

Table 1. Mineral classification-hyperspectral data analysis vs. XRD analysis.

\begin{tabular}{|c|c|c|}
\hline ROI & Hyperspectral Data Analysis ${ }^{1,2}$ & XRD Analysis (from Major to Minor) ${ }^{2}$ \\
\hline A & Kaolinite & Calcite, Kaolinite, Quartz, Dolomite, Iron oxides \\
\hline $\mathrm{B}$ & Quartz, Kaolinite & Quartz, Calcite, Kaolinite, Iron oxides \\
\hline $\mathrm{C}$ & Calcite, Quartz & Calcite, Quartz, Dolomite, Kaolinite, Iron oxides \\
\hline $\mathrm{D}$ & Dolomite, Calcite & Dolomite, Calcite, Quartz \\
\hline $\mathrm{E}$ & Gypsum, Quartz & Gypsum, Quartz, Brushite \\
\hline $\mathrm{F}$ & Gypsum, Calcite, Dolomite & Quartz, Gypsum, Calcite, Dolomite, Brushite \\
\hline G & Feldspars, Quartz & Albite-low, Quartz, Clinochlore \\
\hline $\mathrm{H}$ & Quartz, Kaolinite & Quartz, Calcite, Dolomite, Kaolinite, Iron oxides \\
\hline $\mathrm{I}$ & Quartz, Calcite, Dolomite & Quartz, Calcite, Kaolinite, Dolomite, Iron oxides \\
\hline $\mathrm{J}$ & Quartz, Calcite, Dolomite & Calcite, Quartz, Dolomite, Kaolinite, Iron oxides \\
\hline $\mathrm{K}$ & Quartz , Kaolinite & Quartz, Calcite, Iron oxides \\
\hline $\mathrm{L}$ & Quartz, Kaolinite, Calcite & Calcite, Quartz, Kaolinite, Iron oxides, Dolomite \\
\hline M & Quartz , Calcite, Dolomite & Quartz, Calcite, Dolomite \\
\hline $\mathrm{N}$ & Quartz, Kaolinite & Quartz, Calcite \\
\hline $\mathrm{O}$ & $\begin{array}{l}\text { Gypsum, Quartz, Calcite, } \\
\text { Dolomite, Kaolinite }\end{array}$ & $\begin{array}{l}\text { Dolomite, Gypsum, Calcite, Quartz, Kaolinite, } \\
\text { Titanium dioxide }\end{array}$ \\
\hline $\mathrm{P}$ & Quartz, Calcite, Dolomite & Calcite, Quartz, Dolomite, Kaolinite \\
\hline Q & Gypsum , Quartz, Dolomite, Calcite & $\begin{array}{l}\text { Gypsum, Quartz, Dolomite, Calcite, Iron oxides, } \\
\text { Titanium dioxide }\end{array}$ \\
\hline $\mathrm{R}$ & Calcite, Dolomite, Quartz, Feldspars & Calcite, Quartz, Dolomite, Albite \\
\hline
\end{tabular}

${ }^{1}$ Classification based on the SWIR (magenta), LWIR (blue) and both (black) data; ${ }^{2}$ Dominant mineral in bold.

Clay minerals and carbonates were identified in both SWIR and LWIR data (Figure 3a,b). $90 \%$ of the pixels identified with carbonates were identified in both SWIR (as calcite or dolomite) and LWIR (as carbonates) data sets, strengthening the attribution of the absorption features at 2.32 and $2.34 \mu \mathrm{m}$ 
and $11.2 \mu \mathrm{m}$ (Notesco et al. [7]) to carbonates; however, only $10 \%$ of the pixels identified with clay minerals were identified in both SWIR (as kaolinite) and LWIR (as clay minerals) data sets (Figure 4). This is explained by the proximity of the spectral features of kaolinite and quartz in the LWIR emissivity (Figure 5). ROI A, with a relative large amount of kaolinite (according to XRD analysis), was identified in both SWIR and LWIR data whereas ROI B, with a relative large amount of quartz and less kaolinite (according to XRD analysis, Table 1), was identified as kaolinite in the SWIR data and as quartz in the LWIR data. About $10 \%$ of the pixels identified with kaolinite in the SWIR data were identified with gypsum in the LWIR data (Figure 4). ROI E, with a relative large amount of gypsum and no kaolinite (according to XRD analysis, Table 1), was identified as kaolinite in the SWIR data and as gypsum in the LWIR data (Figure 5). The proximity of the absorption at $2.20 \mu \mathrm{m}$ of gypsum and kaolinite may lead to "false kaolinite" identification in the SWIR data. However, gypsum can be identified in the LWIR data with its noticeable feature at $8.63 \mu \mathrm{m}$. Thus, when classifying kaolinite pixels in the SWIR image (Figure 3a), we omitted the pixels identified as gypsum in the LWIR image (Figure 3b). Note that the presence of small amounts of kaolinite in such pixels cannot be completely negated.

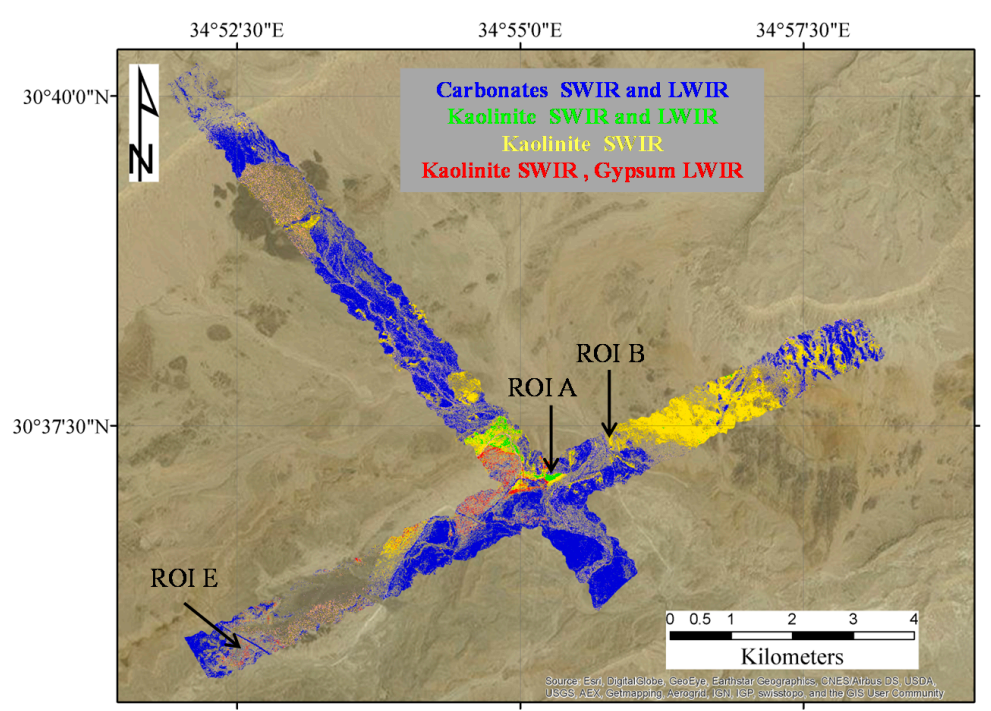

Figure 4. Identification of minerals in both SWIR and LWIR data sets or in only one-SWIR or LWIR-data set.
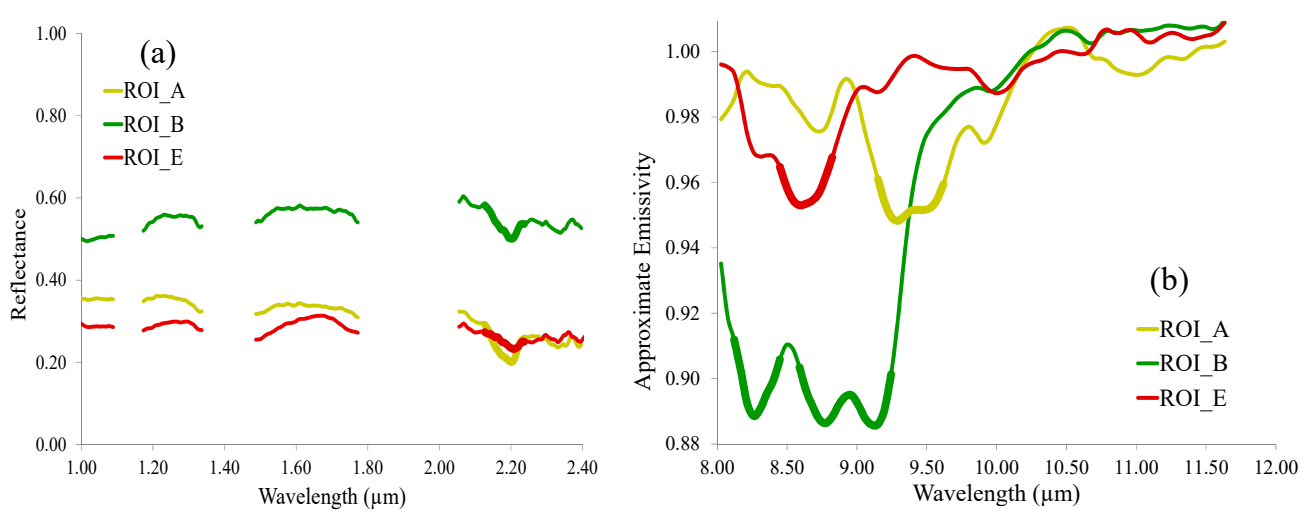

Figure 5. SWIR reflectance spectra (a) and LWIR approximate emissivity spectra (b) of ROIs A, B and E. The relevant features are emphasized with thick lines for the identified minerals. Atmospheric water vapor absorptions were omitted from SWIR reflectance spectra.

The overall mineralogy in each pixel (combining both SWIR and LWIR classification) was determined by giving an arbitrary number to each binary image, representing a specific mineral, and then summing all of these images. 
The combined mineral map is shown in Figure 6 and is compared to the geological map of the area. Across flight line 1, the mineralogy changes from gypsum-, carbonates- and kaolinite-dominant rocks (Mohila formation "tr3") in the southwest part, interrupted by intrusion of feldspars-dominant basalt rocks ("im"), to carbonates-, quartz- and kaolinite-dominant rocks (Mishor and Ardon formations "j11"), to quartz- and kaolinite- dominant rocks (Inmar formation "j12") and quartz-, kaolinite- and carbonates-dominant rocks in the northeastern part (Kurnub group "lck"). The addition of carbonates in the northeastern part is from weathering processes occurring in the carbonates-dominant Har Ardon (700 m above sea level) rocks (Hevyon formation "c1", outside the flight line) to the lower (500 $\mathrm{m}$ above sea level) quartz- and kaolinite-dominant rocks. Across flight line 2, with a gradual elevation from 420 to $740 \mathrm{~m}$ above sea level (southeast to northwest), the mineralogy changes from carbonates-, gypsum- and kaolinite-dominant Mohila formation ("tr3") rocks to kaolinite-, quartz- and carbonates-dominant Alluvium (" $\mathrm{q}$ ") and Inmar formation ("j12") rocks. The quartz-dominant "S shape" in the southeast part is related to sedimentation processes along Nahal Ramon (a dry wadi) stream. The carbonates supplement to the quartz and kaolinite in Inmar formation rocks demonstrates the contribution of weathering processes in the elevated carbonates-dominant Hevyon formation ("c1") and En Yorqe'am, Zafit and Avnon formations ("c2") rocks. The northwest part is interrupted by an intrusion of feldspars-dominant basalt rocks ("ßlc"). The classification of dominant minerals based on the SWIR and LWIR data is compatible with the rock types, demonstrating the ability of combined hyperspectral technology to identify a variety of minerals and mapping their distribution in the surface.

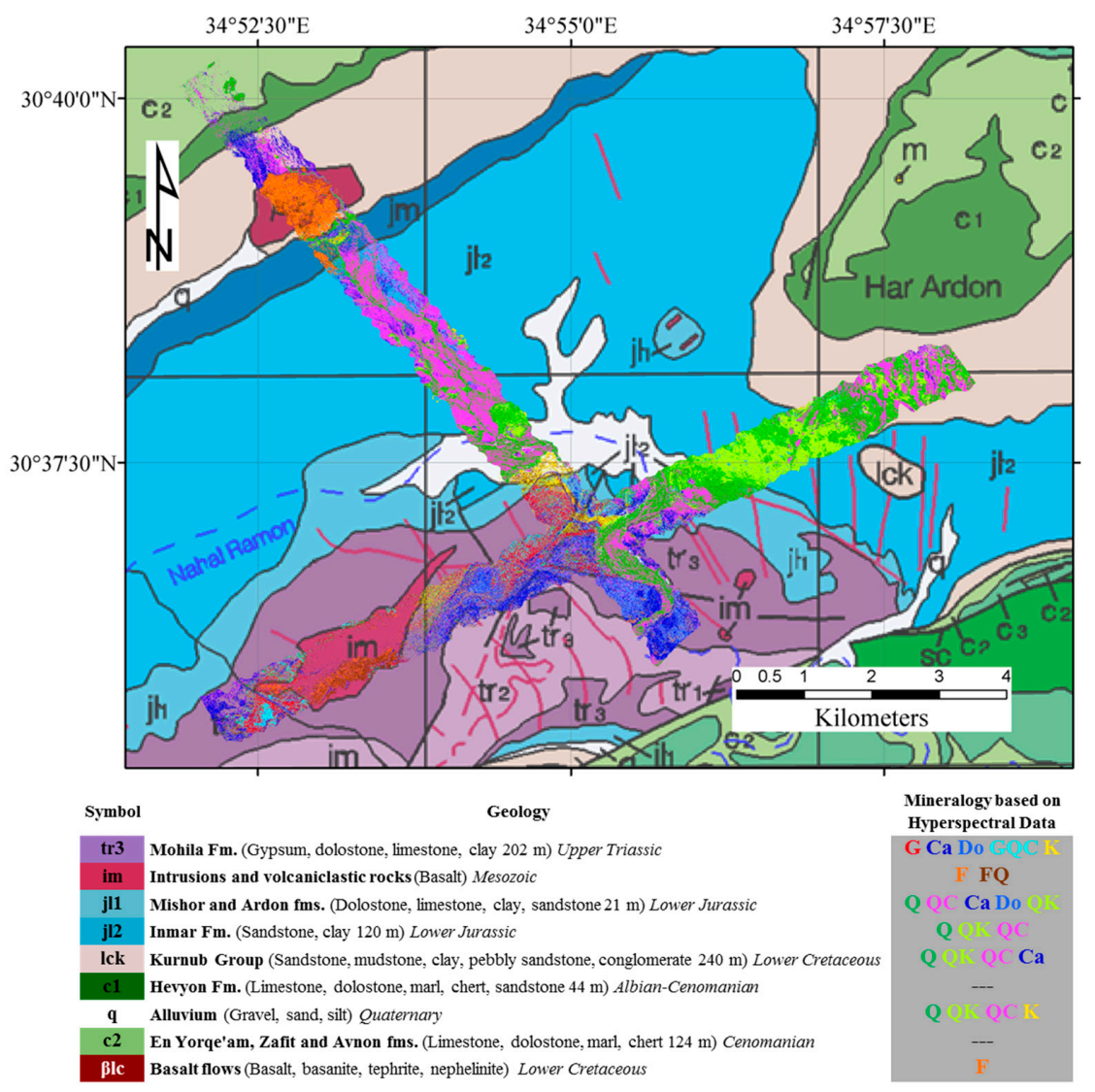

Figure 6. Mineral map of the surface of Makhtesh Ramon on the geological map of the area (source: Sneh, A., Bartov, Y., Weissbrod, T. and Rosensaft, M., 1998. Geological Map of Israel, 1:200,000. Isr. Geol. Surv.). The table shows the rock types in the study area and the mineral classification based on the hyperspectral data: Q-quartz, Ca—calcite, Do-dolomite, QC—quartz + carbonates (calcite, dolomite), K-kaolinite, QK-quartz + kaolinite, F-feldspars, FQ—feldspars + quartz, G-gypsum, GQC-gypsum + quartz (+ carbonates). 


\section{Summary and Conclusions}

This study presents the ability to identify minerals and map their distribution in the surface using hyperspectral remote-sensing data in the SWIR and LWIR regions. Two airborne data sets, acquired with AisaFENIX and AisaOWL sensors over Makhtesh Ramon in Israel, were analyzed. The reflectance spectrum of each pixel in the SWIR images was calculated by applying an atmospheric correction procedure to the radiance images and the 2.0-2.4 $\mu \mathrm{m}$ spectral range was analyzed, enabling identification of kaolinite, calcite and dolomite. The approximate emissivity spectrum of each pixel in the LWIR images was calculated by applying a procedure described by Notesco et al. [7], and the 8.0-12.0 $\mu \mathrm{m}$ spectral range was analyzed, enabling identification of quartz and feldspars (minerals that are featureless in the SWIR region), clay minerals, gypsum and carbonates. Combining the results demonstrated the benefit of using both SWIR and LWIR data sets to identify a variety of minerals and improve their classification. For example, pixels with a relative large amount of quartz and less kaolinite (according to XRD analysis) were identified as quartz only in the LWIR data and as kaolinite only in the SWIR data. The ability to identify gypsum in the LWIR data enabled eliminating "kaolinite false-positive" identification in the SWIR data. The resultant mineralogy was in quite good agreement with the mineralogy of selected rock samples, which were collected from the study area as derived from XRD analysis. The resulting combined mineral map, classifying the dominant minerals in each pixel in the images, was in agreement with the geological map of the area. The results of this study emphasize the importance of integrating both RIR and TIR hyperspectral technology for better mineral mapping of the earth's surface.

Acknowledgments: This study was supported by the Israeli Ministry of Defense fund 00340001000, grant no. 4440554317, the Israeli Ministry of Science, Technology and Space fund 00040047000, grant No. 3-8163 and the Israel Science Foundation fund 00010001000, grant No. 1395/15.

Author Contributions: G.N. processed the data and analyzed the results; Y.O. helped with the geological map and its interpretation; E.B.D. was the project supervisor and participated in all stages of the work.

Conflicts of Interest: The authors declare no conflict of interest.

\section{References}

1. Crowley, J.K. Mapping playa evaporite minerals with AVIRIS Data: A first report from Death Valley, California. Remote Sens. Environ. 1993, 44, 337-356. [CrossRef]

2. Gabr, S.; Ghulam, A.; Kusky, T. Detecting areas of high-potential gold mineralization using ASTER data. Ore Geol. Rev. 2010, 38, 59-69. [CrossRef]

3. Kruse, F.A.; Boardman, J.W.; Huntington, J.F. Comparison of airborne hyperspectral data and EO-1 Hyperion for mineral mapping. IEEE Trans. Geosci. Remote Sens. 2003, 41, 1388-1400. [CrossRef]

4. Vaughan, R.G.; Calvin, W.M.; Taranik, J.V. SEBASS hyperspectral thermal infrared data: Surface emissivity measurement and mineral mapping. Remote Sens. Environ. 2003, 85, 48-63. [CrossRef]

5. Notesco, G.; Kopačková, V.; Rojík, P.; Schwartz, G.; Livne, I.; Dor, E.B. Mineral classification of land surface using multispectral LWIR and hyperspectral SWIR remote-sensing data: A case study over the Sokolov lignite open-pit mines, the Czech Republic. Remote Sens. 2014, 6, 7005-7025. [CrossRef]

6. McDowell, M.L.; Kruse, F.A. Integrated visible to near infrared, short wave infrared, and long wave infrared spectral analysis for surface composition mapping near Mountain Pass, California. In Algorithms and Technologies for Multispectral, Hyperspectral, and Ultraspectral Imagery XXI (Procedings of SPIE); Velez-Reyes, M., Kruse, F.A., Eds.; SPIE Press: Bellingham, WA, USA, 2015; Volume 9472.

7. Notesco, G.; Ogen, Y.; Ben-Dor, E. Mineral classification of Makhtesh Ramon in Israel using hyperspectral longwave infrared (LWIR) remote-sensing data. Remote Sens. 2015, 7, 12282-12296. [CrossRef]

8. Dor, E.B.; Kruse, F.A. Surface mineral mapping of Makhtesh Ramon Negev, Israel using GER 63 channel scanner data. Int. J. Remote Sens. 1995, 16, 3529-3553.

9. The Specim AisaFENIX System. Available online: http://www.specim.fi/index.php/products/airborne/ aisafenix (accessed on 28 January 2016). 
10. Clark, R.N.; King, T.V.V.; Klejwa, M.; Swayze, G.A. High spectral resolution reflectance spectroscopy of minerals. J. Geophys. Res. 1990, 95, 12653-12680. [CrossRef]

11. Hass, M.; Sutherland, G.B.B.M. The infra-red spectrum and crystal structure of gypsum. Proc. R. Soc. A 1956, 236A, 427-445. [CrossRef]

12. The USGS Spectral Library. Available online: http://speclab.cr.usgs.gov/spectral-lib.html (accessed on 28 January 2016).

13. The Arizona State University Spectral Library. Available online: http://speclib.asu.edu (accessed on 28 January 2016).

14. Clark, R.N.; King, T.V.V.; Gorelick, N.S. Automatic continuum analysis of reflectance spectra. In Proceedings of the Third AIS Workshop, Pasadena, CA, USA, 2-4 June 1987; JPL Publication: Pasadena, CA, USA, 1987; pp. 138-142.

15. Kruse, F.A.; Lefkoff, A.B.; Dietz, J.B. Expert system-based mineral mapping in northern Death Valley, California/Nevada using the Airborne Visible/Infrared Imaging Spectrometer (AVIRIS). Remote Sens. Environ. 1993, 44, 309-336. [CrossRef]

16. Kruse, F.A.; Thiry, M.; Hauff, P.L. Spectral identification (1.2-2.5 $\mu \mathrm{m})$ and characterization of Paris basin kaolinite/smectite clays using a field spectrometer. In Proceedings of the 5th International Colloquium on Physical Measurements and Signatures in Remote Sensing, Courchevel, France, 14-18 January 1991; Volume 1, pp. 181-184.

17. Van der Meer, F. Analysis of spectral absorption features in hyperspectral imagery. Int. J. Appl. Earth Observ. Geoinf. 2004, 5, 55-68. [CrossRef]

(C) 2016 by the authors; licensee MDPI, Basel, Switzerland. This article is an open access article distributed under the terms and conditions of the Creative Commons Attribution (CC-BY) license (http://creativecommons.org/licenses/by/4.0/). 